\title{
Aerobic Variables for Prediction of Alpine Skiing Performance - A Novel Approach
}

\section{(c) (i) (으 $\Theta$}

\author{
Authors \\ Robert Nilsson ${ }^{1}$, Ann-Sofie Lindberg ${ }^{2}$, Apostolos Theos ${ }^{1}$, Richard A. Ferguson ${ }^{3}$, Christer Malm ${ }^{1}$
}

\author{
Affiliations \\ 1 Department of Community Medicine and Rehabilitation, \\ Sports Medicine Unit, Umea University, Umeå, Sweden \\ 2 Winternet, Boden, Sweden \\ 3 School of Sport, Exercise and Health Sciences, Loughbor- \\ ough University School of Sport Exercise and Health \\ Sciences, Loughborough, United Kingdom of Great \\ Britain and Northern Ireland
}

Key words exercise testing, athletic performance, FIS points, multivariate statistics, $\dot{\mathrm{V} O} 2 \mathrm{max}$

$\begin{array}{ll}\text { received } & 08.05 .2018 \\ \text { revised } & 05.06 .2018 \\ \text { accepted } & 07.06 .2018\end{array}$

\section{Bibliography}

DOI https://doi.org/10.1055/a-0655-7249

Sports Medicine International Open 2018; 2: E105-E112

(c) Georg Thieme Verlag KG Stuttgart · New York

ISSN 2367-1890

Correspondence

Mr. Robert Nilsson

Department of Community Medicine and Rehabilitation

Sports Medicine Unit

Umea University

Gösta Skoglunds väg 33

Umeå

90187

Sweden

Tel.: + 46/90/786 50 00, Fax: + 46/90/135692

robert.nilsson@umu.se

\begin{abstract}
The aim of this study was to investigate the predictive power of aerobic test results and anthropometric variables on FISranking of junior elite alpine skiers. Results from twenty-three male and female adolescent elite alpine skiers from two seasons were included in the multivariate statistical models. Physical work capacity was determined by VंO2peak, blood lactate concentration ([HLa]b), and heart rate (HR) during ergometer cycling. Anthropometric variables were body stature, body weight and calculated BMI. No significant correlation between competitive performance and aerobic work capacity or anthropometric data was observed neither in male nor female adolescent skiers. Pre-season physical tests and anthropometric data could therefore not predict end-season FISranking. The best regression (R2) and prediction (Q2) models of FIS slalom (SL) and giant slalom (GS) rank reached $\mathrm{R} 2=0.51$ to $0.86, \mathrm{Q} 2=-0.73$ to 0.18 , indicating no valid models. This study could not establish $\dot{V}$ O2peak and other included variables as predictors of competitive performance. When combining results from commonly used tests for alpine skiers, and applying multivariate statistical models, investigated tests seems of limited used for athletes, coaches, and ski federations. Performance-specific pre-season tests must be developed and validated for prediction of performance and guidance of exercise training.
\end{abstract}

\section{Introduction}

Competitive alpine skiing is regarded as the world's fastest nonmotorized sport [5] and consists primarily of four different disciplines: slalom (SL), giant slalom (GS), super giant slalom (SG) and downhill (DH), the latter two being referred to as speed events. Each of these disciplines differs in turning radius, gate distance, speed, and length of the course [41]. The two more technical dis- ciplines (SL and GS) run on relatively steep terrain at speeds between $20-60 \mathrm{~km} \cdot \mathrm{h}^{-1}$ for $45-90 \mathrm{~s}$, whereas the speed disciplines are carried out on long, steep slopes at speeds reaching 130 $160 \mathrm{~km} \mathrm{~h}^{-1}$ and lasting $120-180 \mathrm{~s}[10,32]$. Due to the intermittent nature of the sport with rapid shifts in directions at high-speed [27], alpine ski racing is a demanding and multi-faceted sport requiring high levels of physical and technical competence [37]. 
Elite performance in alpine skiing requires a wide range of physical qualities, including high muscular strength and endurance, as well as a broad range of neuromuscular skills such as balance, speed, and agility [2, 20,41]. Anthropometric characteristics may also affect performance [1, 2, 37], especially in young athletes $[8,14]$. High aerobic capacity has been described as an important physical quality of an alpine skier [23, 31] and today it is considered, at least by coaches, athletes and federations, an important physiological determinant of competitive success. However, few findings support this assertion. Inconsistent findings regarding required metabolic capacities for optimal competitive performance are reported; some researchers find a significant correlation between maximum absolute and relative aerobic capacity $\left(\dot{\mathrm{V}}_{2 \max }\right)$ and competitive performance in elite alpine skiers [13, 21], whereas others do not [41]. Furthermore, $\dot{\mathrm{V}} \mathrm{O}_{2 \max }$ could not discriminate between skiers at different performance levels $[6,40]$.

Instead, several contemporary studies show a correlation between anaerobic power and ski performance $[3,6,13,39,41]$. With race times of 45-180 s, both aerobic and anaerobic energy systems are utilized [29], which possibly contributes to the disagreements between studies [24]. Hence, the importance of the respective metabolic system is still a matter of debate $[19,22,24,30]$. Technical events (SL, GS) have a larger relative anaerobic component compared to the faster and longer-duration disciplines (SG, DH) $[38,39]$. Differences in skiing technique, mechanical work, and overall skills will also result in differences in the relative utilization of energy systems $[27,38]$.

In alpine skiing, long-term, or summarized, competitive performance is quantified by the Fédération Internationale de Ski (FIS) point scoring system, based on practitioners' results in each disci- pline during the racing season. In brief, FIS points are matched so that the best skier in the world in every discipline has 0 points and the 30 th has 6 points, per season. The point system is therefore a measure of where each practitioner stands against other practitioners. The points system is adjusted several times annually and can be found, along with detailed information about the ranking system, at www.fis-ski.com.

Because of the complexity of the sport, with a mixed utilization of energy systems and lack of consistent research finding, the selection of useful sport-specific tests of physiological capacities is challenging. Consequently, coaches and athletes are dependent on nonreliable tests for planning and evaluating training. This study will use advanced multivariate statistics, the validity of which has been demonstrated in other similar contexts [17], to investigate relationships between results from commonly used aerobic tests and anthropometric variables and their value to predictive alpine skiing performance. By focusing on aerobic tests, results from this study will guide future research towards more specific testing procedures. Omitting all or any irrelevant tests will save time and money for sports federations and sports clubs alike, as well as help coaches and athletes to optimize training, evaluation and racing performance.

\section{Materials \& Methods}

\section{Subjects}

Anthropometric data and aerobic test results from a total of twenty-three elite junior alpine skiers, aged 16-17 years, were included in the study ( $\triangleright$ Table 1 ). All participants provided their written, informed consent for participation and parental/guardian consent was

- Table 1 Anthropometric data and aerobic test results.

\begin{tabular}{|c|c|c|c|c|}
\hline Variable & Male & & Female & \\
\hline Age group & Age 17 yr $(n=10)$ & Age $16 \mathrm{yr}(n=13)$ & Age 17 yr $(n=6)$ & Age $16 \mathrm{yr}(n=10)$ \\
\hline Body weight $(\mathrm{kg})$ & $75.4 \pm 5.3$ & $69.2 \pm 5.5$ & $68.1 \pm 3.7$ & $69.7 \pm 3.4$ \\
\hline Body height (m) & $178 \pm 5$ & $178 \pm 5$ & $170 \pm 6$ & $172 \pm 4$ \\
\hline $\mathrm{BMI}\left(\mathrm{kg} \cdot \mathrm{m}^{-2}\right)$ & $24 \pm 1$ & $22 \pm 1$ & $24 \pm 1$ & $24 \pm 2$ \\
\hline HR at aerobic ventilatory threshold (bmp) & $128.8 \pm 18.0$ & $126.5 \pm 21.4$ & $129.6 \pm 17.9$ & $125.7 \pm 12.9$ \\
\hline $\begin{array}{l}\dot{\mathrm{V}} \mathrm{O}_{2} \text { at aerobic ventilatory threshold } \\
\left(\mathrm{L} \cdot \mathrm{min}^{-1}\right)\end{array}$ & $1.6 \pm 0.20$ & $1.5 \pm 0.5$ & $1.3 \pm 0.4$ & $1.1 \pm 0.2$ \\
\hline $\begin{array}{l}\text { HR at aerobic ventilatory threshold by } \\
\text { Wasserman (bpm) }\end{array}$ & $163.2 \pm 10.7$ & $157.3 \pm 19.5$ & $162.3 \pm 12.7$ & $155 \pm 14$ \\
\hline $\begin{array}{l}\dot{\mathrm{V}} \mathrm{O}_{2} \text { at anaerobic threshold by Wasserman } \\
\left(\mathrm{L} \cdot \mathrm{min}^{-1}\right)\end{array}$ & $2.6 \pm 0.5$ & $2.4 \pm 0.4$ & $2 \pm 0.3$ & $1.8 \pm 0.3$ \\
\hline $\mathrm{HR}$ at $2.00 \mathrm{mmol} \cdot \mathrm{L}^{-1}[\mathrm{HLa}]_{\mathrm{b}}$ & $159.9 \pm 12.4$ & $160.1 \pm 11.3$ & $160.9 \pm 15.3$ & $169.2 \pm 8.3$ \\
\hline$\dot{\mathrm{V}} \mathrm{O}_{2}$ at $2.00 \mathrm{mmol} \cdot \mathrm{L}^{-1}[\mathrm{HLa}]_{\mathrm{b}}$ & $2.4 \pm 0.5$ & $2.5 \pm 0.3$ & $2.0 \pm 0.3$ & $2.2 \pm 0.3$ \\
\hline HR at RER 1.00 & $181.6 \pm 9.9$ & $175.2 \pm 14.8$ & $175.8 \pm 13.5$ & $177 \pm 10.4$ \\
\hline$\dot{\mathrm{V}} \mathrm{O}_{2}$ at RER 1.00 & $3.3 \pm 0.4$ & $3.0 \pm 0.6$ & $2.5 \pm 0.3$ & $2.5 \pm 0.3$ \\
\hline $\mathrm{HR}$ at OBLA & $182.2 \pm 7.4$ & $179.9 \pm 11.7$ & $180.3 \pm 12.3$ & $185.5 \pm 8.6$ \\
\hline$\dot{\mathrm{V}} \mathrm{O}_{2}$ at $\mathrm{OBLA}$ & $3.3 \pm 0.3$ & $3.2 \pm 0.4$ & $2.6 \pm 0.2$ & $2.9 \pm 0.2$ \\
\hline Maximal HR & $199.8 \pm 5.6$ & $199.7 \pm 8.5$ & $195.8 \pm 8.2$ & $193.3 \pm 8.1$ \\
\hline Maximal absolute $\dot{\mathrm{V}} \mathrm{O}_{2}\left(\mathrm{~L} \cdot \mathrm{min}^{-1}\right)$ & $4.4 \pm 0.4$ & $4.1 \pm 0.4$ & $3.3 \pm 0.3$ & $3.2 \pm 0.2$ \\
\hline Maximal relative $\dot{\mathrm{V}} \mathrm{O}_{2}\left(\mathrm{ml} \cdot \mathrm{min} \cdot \mathrm{kg}^{-1}\right)$ & $58.2 \pm 4.4$ & $58.6 \pm 2.6$ & $48.4 \pm 2.3$ & $46.5 \pm 2.4$ \\
\hline FIS ranking points & & & & \\
\hline
\end{tabular}


obtained for minors. Some participants were tested more than once, as indicated in the data. Ethical permission Dnr 2011-236-31 M was granted by the ethical committee for northern Sweden at Umeå University, and the study was conducted in accordance with the World Medical Association Declaration of Helsinki - Ethical Principles for Medical Research Involving Human Subjects 2008 and the ethical standards of the International Journal of Sports Medicine [12].

\section{Methodology}

Analyzed data were compiled from both aerobic and anthropometric tests conducted at the Department of Sports Medicine, Umea University, Sweden. All participants included in the study were asked to refrain from any strenuous physical activity the day before the tests and to follow the same routine with respect to e. g., sleep and nutritional intake, before all test occasions. Before each test occasion, the participants were asked to complete a health questionnaire regarding previous exercise training, nutritional intake and disease history. Exclusion criteria included any injury and/or history of hormonal, metabolic or cardiovascular diseases.

Slalom and GS FIS ranking points were collected twice, in December ( $6^{\text {th }}$ list) and April ( $11^{\text {th }}$ list) and correlated to the pre-season testing in June-July and October-December. Data were sorted into categories by SL, GS, sex, year of birth and national ranking (Sweden). In brief, FIS ranking was used as a measurement of competitive performance (the $\mathrm{Y}$-variable in all statistical analyses), and maximal physiological capacity including $\dot{\mathrm{V}}_{2}$, heart rate, and blood lactate were measured during a maximal cycling ergometer test (X-variables). Anthropometric variables recorded were body mass and stature. BMI calculation was based on the following formula: $\mathrm{BMI}=$ body mass $(\mathrm{kg}) /[\text { stature }(\mathrm{m})]^{2}$ (X-variables).

Before each test session, a short medical exam was performed, including resting blood pressure. Body mass was measured using a standard weight scale (Soehnle weighing scale, Leifheit AG, Nassau, Germany), and body stature was measured using a wallmounted scale (Fosamax stadiometer, Merck \& Co. Inc., Kenilworth, $\mathrm{NJ}$, USA). A peripheral venous catheter (Optiva 2 radiopaque I.V. catheter, $L=32 \mathrm{~mm}, \varnothing=1.10 \mathrm{~mm}$, Smiths Medical, London, England) was placed in the antecubital vein, and an airtight facial mask (Hans Rudolph Inc., Shawnee, KS, USA) was fitted to cover the subject's airways. At rest, blood samples were collected and subsequently analyzed for hemoglobin concentration (HB) with a HemoCue Hb 201 + (HemoCue AB, Ängelholm, Sweden) and blood lactate concentration $[\mathrm{HLa}]_{b}$ with a YSI 1500 sport analyzer (YSI Life Sciences, Yellow Springs, OH, USA). Maximum performance tests were carried out on a Monark 839E cycle ergometer (Monark, Varberg, Sweden) with an increasing load ( +40 and $30 \mathrm{~W}$ every 3 min, with a starting load of $40 \mathrm{~W}$ for males and $30 \mathrm{~W}$ for females) until exhaustion. Oxygen consumption $\left(\dot{\mathrm{V}}_{2}\right)$ was tested using a calibrated Oxycon Pro Jaeger System (VIASYS Healthcare, Würzburg, Germany) set on mixing chamber mode, and the mean value for the final $30 \mathrm{~s}$ before exhaustion registered as $\dot{\mathrm{V}}_{2 \text { peak. }}$. Heart rate was monitored telemetrically using a Polar Electro s610i (Polar Electro Oy, Kempele, Finland) pulse watch. Blood lactate samples were collected every $3 \mathrm{~min}$ (equivalent to the $3 \mathrm{rd}$ minute of each exercise load). Test results are $\mathrm{X}$-variables in the statistical analysis.

\section{Multivariate statistics - justification and simplified description of PCA and OPLS}

In sports research, the use of bivariate and multivariate linear regression is common [28]. However, using traditional sports research methods may in some cases be an inefficient approach because multivariate data is often hidden and some variables can interact and elicit a specific response [9]. A complex interaction between different qualities determines the performance of an alpine skier [16, 21, 37], making a complete identification and interpretation of valid performance data by means of conventional statistics impossible. Thus, the data in this study have been analyzed using multivariate data analysis (MVDA). Multivariate statistical methods use two or more variables collectively to investigate interactive outcomes. To examine the relationship between anthropometric and physiological variables and the sport-specific performance of alpine skiing, principal component analysis (PCA) and orthogonal projections to latent structures (OPLS) statistical methods were applied. Principal component analysis is a relatively simple method that can be used to investigate how observations and variables relate to each other and to find hidden structures or patterns in data, all by reducing data dimensions $[9,15]$.

Orthogonal projections to latent structures is a statistical method that is considered an extended version of PCA and is often used to find the linear relationship between two groups of variables [9]. Similar to PCA, observations in OPLS are assumed to be affected only by a few indivisible underlying variables. To facilitate the identification of these variables, estimations of the observations are therefore calculated. The difference from PCA, however, is that each observation in the data matrices is now expressed as two separate point coordinates, with one projected into the $X$ space and the other into the $Y$ space [45]. Orthogonal projections to latent structures is then used to examine whether there is a correlation between these point coordinates, one in each multivariate space, to predict $Y$ based on $X$ [35]. Thus, the regression in OPLS is calculated by the covariance between $Y$ and $X$ instead of the variance within $X$, iteratively by testing the predictive ability of previous components until the new model is not considered significant when the procedure stops. Cross-validation by permutation is used to determine the number of regression components that should be included in the model [35]. For more in-depth reading on the statistical methods, we refer to the published literature $[7,9,15,36,44]$.

\section{Statistical analysis}

Prediction of FIS ranking (Y-variables) was achieved from anthropometric and physiological test results (X-variables). $R^{2} V Y$ is the cumulative percent of the variation of the response explained by the model after the last component. $R^{2}$ is a measure of fit, i. e., how well the model fits the data. $R^{2}$ VYAdj is the cumulative percent of the variation of the response, adjusted for degrees of freedom, explained by the model after the last component. $\mathrm{Q}^{2} \mathrm{VY}$ is the cumulative percent of the variation of the response predicted by the model, after the last component, according to cross-validation. $\mathrm{Q}^{2}$ indicates how well the model predicts new data. A useful model should have a large $R^{2}$ and $Q^{2}$. To evaluate the importance of variables for FIS ranking, an analysis of variable influence on projection (VIP) was executed. In an OPLS model, VIP summarizes the impor- 
tance of the $\mathrm{X}$-variables, both for the $\mathrm{X}$ - and $\mathrm{Y}$-models. VIP is normalized, and the average squared VIP value is 1 ; thus a VIP $>1$ indicates that the variable is important for the projection, and values lower than 0.5 indicate that the variable is unimportant for the projection. An $R^{2}$ and a $Q^{2}>0.60$ were deemed valid. The significance is set by rules 1, 2 and 3, where $\mathrm{Q}^{2}>$ Limit (indicated as R1, R2 and $\mathrm{R} 3$ in Results, where the Limit depends on a number of components for PCA and Y-variables for OPLS (extract from the SIMCA-P + Handbook)).

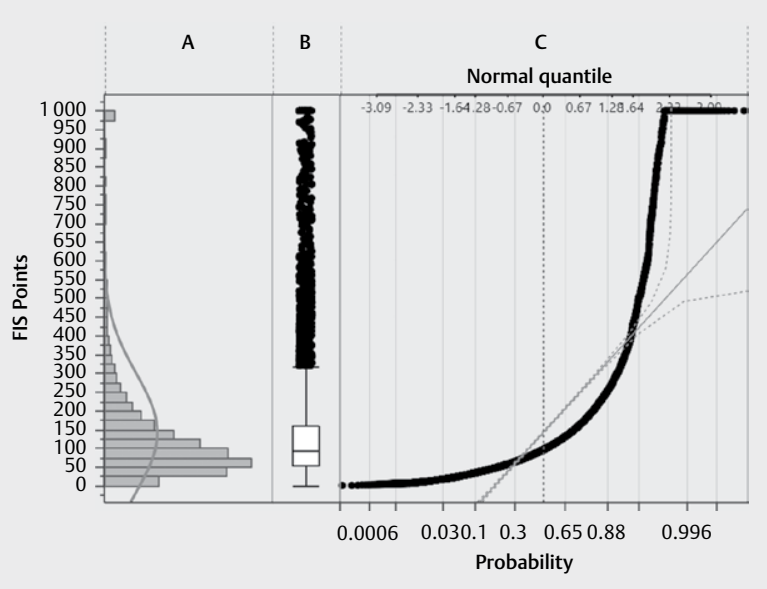

-Fig. 1 Three different distribution plots of FIS points in SL, with data treated as a continuous variable. a) Histogram of FIS point distribution with the normal continuous fit (red line). b) Outlier box plot displays the distribution and identifies possible outliers in data, with the box plot showing $25^{\text {th }}$ and $75^{\text {th }}$ percentile, whiskers at $1^{\text {st }}$ quartile - $\left(1{ }^{*}\right.$ interquartile range $)$ and $3^{\text {rd }}$ quartile $+\left(1.5^{*}\right.$ interquartile range).c) Normal quantile plot visualizes the extent to which the variable is normally distributed. If a variable is normally distributed, the normal quantile plot approximates a diagonal straight (solid red) line. The normal quantile plot also shows Lilliefors confidence bounds (dashed red line) and probability (below) and normal quantile (above) scales. All three plots indicate that data do not have a normal distribution (goodness-of-fit test $\mathrm{p}<0.01$ ).
Physiological and anthropometric variables were distributed normally according to Shapiro-Wilk goodness-of-fit test $(p<0.05)$. Because FIS points and rankings are ordinal, parametric statistics cannot be applied. If treated as continuous data, as in other publications, FIS points do not have a normal distribution ( $>$ Fig. 1; Shapiro-Wilk goodness-of-fit test $p>0.01$ ), which also suggests the use of non-parametric methods. Data were analyzed using SIMCA 14.0 (MKS AB, Umeå, Sweden) and JMP 13.1 (SAS Institute Inc., Cary, NC, USA).

\section{Results}

Anthropometric and physiological test results are presented in - Table 1. There was no significant correlation between $\dot{\mathrm{VO}}_{2 \text { peak }}$ and FIS ranking ( $\vee$ Fig. 2). \Table 2 shows OPLS models with cross-validation for each year by sex and discipline. - Fig. 3 is a PCA scatter plot (A) and loading plot (B) showing a clustering of sex based on physical performance ( $\triangleright$ Fig. 3a), where the loading plot indicates higher $\dot{\mathrm{V}}_{2 \text { peak }}$ and lower heart rate in males compared to females ( $>$ Fig. 3b). The correlation of FIS ranking with physical tests and anthropometric data by OPLS in > Fig. 4 indicates a clustering of FIS rank not related to any analyzed variables (not located in the same area of the plot). Of all variables analyzed, BMI is located closest to the FIS rank cluster, but with a weight of 0.2 it is not of significant importance in the models. BMI scores a 2.0 but with large $95 \%$ jackknife uncertainty bars ( $\triangleright$ Fig. 5b). Separation into FIS rank of young elite alpine skiers could not be reliably predicted using results from physiological and anthropometric measurements ( $\triangleright$ Table 2 ). The explanation of variation in the regression models yielded $R^{2}>0.5$ (more than $50 \%$ of the error explained by the components). However, prediction of rank (by cross-validation) could not be made with high confidence when $\mathrm{Q}^{2}<0.3$ in all OPLS analyses ( $\triangleright$ Table 2). As an example, the model for slalom rank in females aged 16 is shown in $>$ Fig. $\mathbf{5}$, where a significant regression model was observed ( Fig. 5a), with BMI as the most important variable ( $>$ Fig. 5b). However, the $\mathrm{R}^{2} / \mathrm{Q}^{2}$ plot ( $\mathbf{F i g} . \mathbf{5 c}$ ) demonstrates a low predictive power $\left(Q^{2}=-0.29\right.$ ), and cross-validation by permutation ( $\vee$ Fig. 6) confirms the low predictive power and rejects the regression model in $>$ Fig. 5 a.
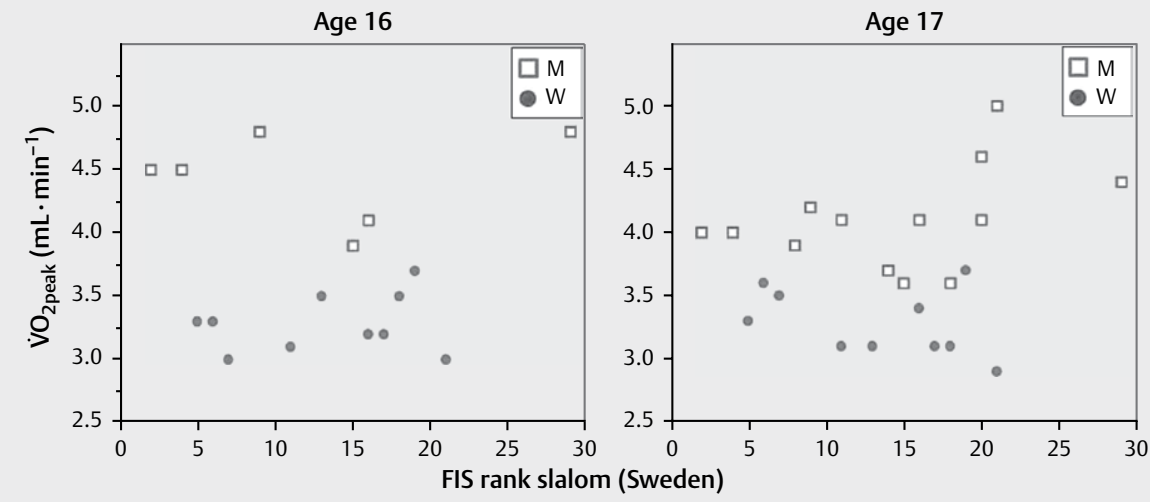

- Fig. 2 Correlation between FIS ranking and peak oxygen consumption. Plot of FIS ranking for Sweden versus peak oxygen consumption ( $\mathrm{VO}_{2 \mathrm{peak}}$, $\left.\mathrm{mL} \cdot \min ^{-1}\right)$. Spearman's rank correlations for Age 16: Male $\rho=0.48 ; p=0.09$. Female $\rho=-0.36 ; p=0.31$. Age 17: Male $\rho=0.03 ; p=0.96$. Female $\rho=0.09 ; p=0.80$. Male, blue squares; female, red dots. Consensus: There is no significant correlation between $\mathrm{VO}_{2 \text { peak }}$ and FIS ranking. 
Table 2 Multivariate models.

\begin{tabular}{|c|c|c|c|c|c|}
\hline Age & FIS rank & Sex & $R^{2} / Q^{2}$ Adj & $\mathrm{R}^{2}$ significance & $\mathrm{Q}^{2}$ cross-validated \\
\hline \multirow[t]{4}{*}{$16(n=23)$} & \multirow[t]{2}{*}{ Slalom } & Female $(n=10)$ & $0.73 /-0.29$ & NS & Yes \\
\hline & & Male $(n=13)$ & $0.61 /-0.58$ & NS & Yes \\
\hline & \multirow[t]{2}{*}{ Giant Slalom } & Female $(n=10)$ & $0.65 /-0.73$ & R1 & Yes \\
\hline & & Male $(n=13)$ & $0.51 /-0.51$ & NS & Yes \\
\hline \multirow[t]{4}{*}{$17(n=16)$} & \multirow[t]{2}{*}{ Slalom } & Female $(n=6)$ & $0.86 / 0.18$ & R1 & Yes \\
\hline & & Male $(n=10)$ & $0.84 /-0.08$ & R1 & No \\
\hline & \multirow[t]{2}{*}{ Giant Slalom } & Female $(n=6)$ & $0.80 /-0.35$ & NS & Yes \\
\hline & & Male $(n=10)$ & $0.82 /-0.19$ & NS & No \\
\hline \multicolumn{6}{|c|}{$\begin{array}{l}\text { Prediction of final }\left(11^{\text {th }}\right) \text { FIS ranking in April each year. } Q^{2} \text { indicates the overall fit and the predictive power of the model. } R^{2} \text { and } Q^{2} \text { should be }>0.5 \text { for } \\
\text { well-modeled data. } Q^{2} \text { cross-validated; assessment of the risk that the model is spurious, i. e., the model fits only the training set well but does not } \\
\text { predict Y well for new observations. Permutation }(n=15) \text { validated models if intercept }<0 \text { or all permutated } Q^{2} \text { values are below original model value. } \\
\text { Thus, a "yes" indicates that the predictive model is valid, but not that it is significant. NS; Not Significant. } R^{2} \text {; significant model when } Q^{2}>\text { limit, with } \\
\text { the limit increased with subsequent components to account for the loss in degrees of freedom in each OPLS model. A valid model should have } \\
\mathrm{R}^{2}>0.8, \mathrm{Q}^{2}>0.5 \text {, significance by R1 and "yes" for } \mathrm{Q}^{2} \text { cross-validation. No model fulfills these criteria. For further details, we refer to SIMCA Support at } \\
\text { https://umetrics.com/sites/default/files/kb/multivariate_fag.pdf. }\end{array}$} \\
\hline
\end{tabular}
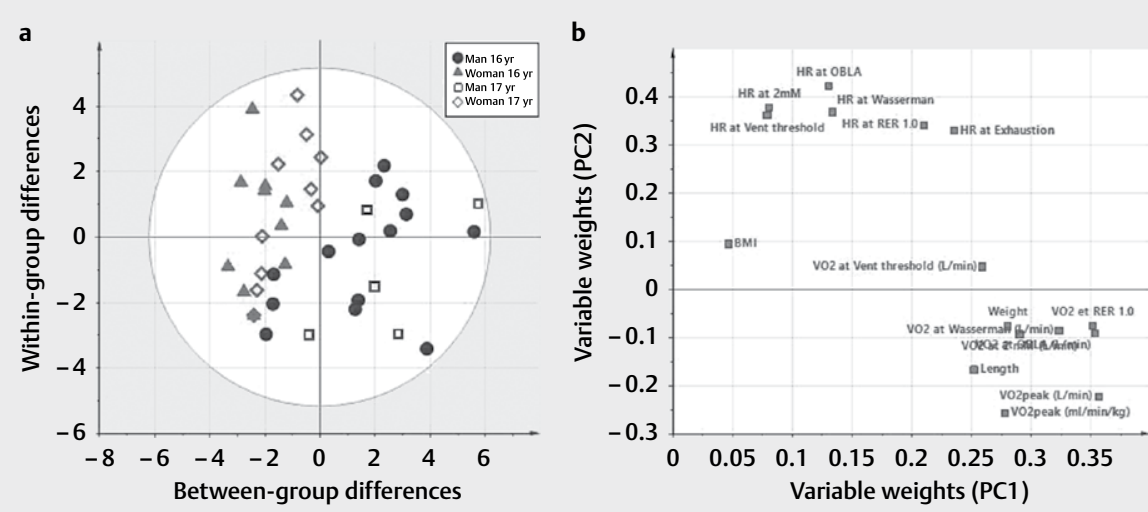

Fig. 3 Principal component analysis of performance tests. a) Score scatter plot visualizes variation in the performance testing data, here seen as between-group differences and within-group differences. Age 16 and 17 data for male and female. Included variables $(X)=16$. Each data point is the total score of one subject. b) Loading scatter plot visualizes correlations between variables: Physical tests located in the same part of the loading plot are correlated. The score plot and the loading plot communicate: subjects located in the same area in the score plot (A), as variables in the loading plot $(B)$, have a high performance within these tests. $n=39$. Consensus: Male and female can be separated based on tests results, but no test result is of significant importance.

\section{Discussion}

The main finding of this study is that aerobic and anthropometric variables cannot predict alpine skiing performance, even when multivariate statistics are applied. In conformity with some previous studies $[6,40]$ but in contrast to others $[11,13,21]$, we could not demonstrate a strong correlation between aerobic work capacity $\left(\dot{\mathrm{V}}_{2 \text { peak }}\right)$ and competitive performance, as indicated by FIS ranking ( $\triangleright$ Fig. 2). Because none of the aerobic or anthropometric variables cluster with any of the FIS rankings ( $>$ Fig. 4 ), the overall interpretation of the findings in this study must be that factors other than those investigated predict long-term performance in alpine skiing among adolescents. This outcome is not surprising, given the large variation in reported aerobic demands during high-intensity alpine skiing, ranging from around $80 \%$ up to $200 \%$ of $\dot{\mathrm{V}} \mathrm{O}_{2 \max } 26,33,38$ ]. Furthermore, the lack of correlation in our calculations can to some extent be a result of the overall skill set of the individual athlete, because differences in skiing economy between practitioners most likely result in a significant variation in the importance of various physiological skills on an individual level. This claim is supported by the fact that the practitioners in the present study, who compete at the national junior level, have similar $\dot{\mathrm{V}}_{2}$ values ( $\triangleright$ Table 1), with a mean of $58 \mathrm{ml} \cdot \min \cdot \mathrm{kg}^{-1}$ for men and $49 \mathrm{ml} \cdot \min \cdot$ $\mathrm{kg}^{-1}$ for women. These numbers are similar to world-class male [21] and female (Swedish national women's team, unpublished data) skiers. Thus, in agreement with previous studies $[6,40]$, it seems that $\dot{\mathrm{V}}_{2 \text { max }}$ is not a discriminating factor between practitioners at different levels and that a relative $\dot{\mathrm{V}}_{2 \max }$ of $\geq 50 \mathrm{ml} \cdot \mathrm{kg} \cdot$ $\mathrm{min}^{-1}$ appears sufficient to be competitive at the highest international level.

As a measurement of anaerobic workload both Saibene et al. [26] and Tesch et al. [33] conclude that high [HLa $]_{b}$ is reached during both SL and GS, without affecting competitive performance ei- 


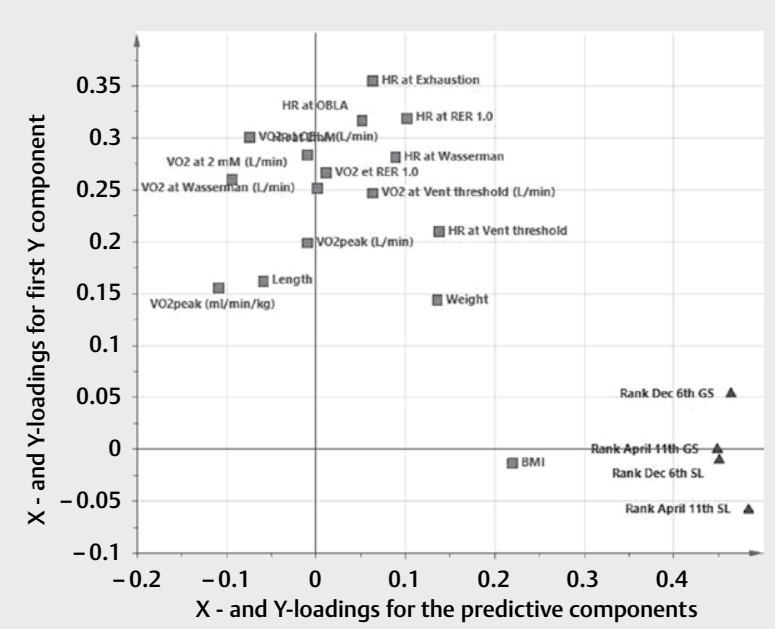

> Fig. 4 Correlations between physical tests and FIS ranking. Data from males and females tested and ranked at age 16 and 17 . Orthogonal partial least squares (OPLS) loading scatter plot $(X=16$, $Y=4 ; n=39$ ) visualizes correlations between variables: Physical tests and FIS rankings located in the same part of the loading plot are correlated. The horizontal axis displays the $\mathrm{X}$ - and $\mathrm{Y}$ - loadings of the predictive component, and the vertical axis the $X$ - and $Y$-loadings for the first $Y$-orthogonal component. A high value $(\max =1)$ means that the component is aligned with the original variable, a value close to zero shows that it has no influence. A low value $(\min =-1)$ indicates an opposite influence. Consensus: None of the included tests are important for FIS ranking in any of the disciplines at any time. ther in elite or sub-elite athletes. Our findings support this conclusion, because no variable measured, including $[\mathrm{HLa}]_{b}$, is of significant importance in any model ( $\triangleright$ Table 2 and $\triangleright$ Fig. 3-6). However, during extensive preparatory periods, $[\mathrm{HLa}]_{b}$ should be considered as an indicator of anaerobic muscle workload, because high $[\mathrm{HLa}]_{b}$ levels have been associated with decreased skiing performance during repeated training runs [42].

As in the present study, Neumayr et al. [21] did not find a correlation between anthropometric variables and performance in elite adult male and female skiers. In contrast, Emeterio et al. [8] observed significant correlations between anthropometric variables and national rank (Spain) in male adolescent skiers. In both studies, conclusions were made that female and male skiers are limited by different performance factors (without any discriminant analysis shown), and that very few quantifiable variables predict future performance among female alpine skiers. This finding is supported by the separation of sexes in > Fig. $\mathbf{3 a}$.

Suggestions have been made that body control and body composition are important for performance in alpine skiing [2, 37]. Thus, it is not surprising that percent body fat is correlated to performance variables in alpine skiing, because smaller and leaner athletes perform better in SL [13], and skiers with a greater fat mass have an advantage in $\mathrm{DH}[13,21]$. Calculated BMI was not a significant factor in our models ( $\triangleright$ Fig. $3-5$ ), yet among the ranked variables ( $\triangleright$ Fig. $\mathbf{5 b}$ ) it ranks as number one but with high variability. Our results, therefore, suggest that body composition may be of importance, but that BMI is an uncertain tool for evaluation.

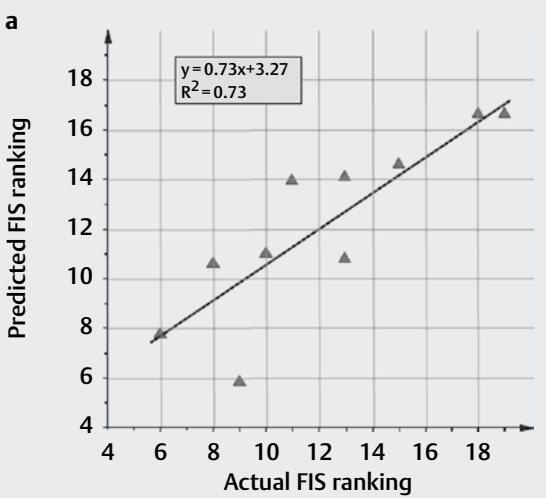

C

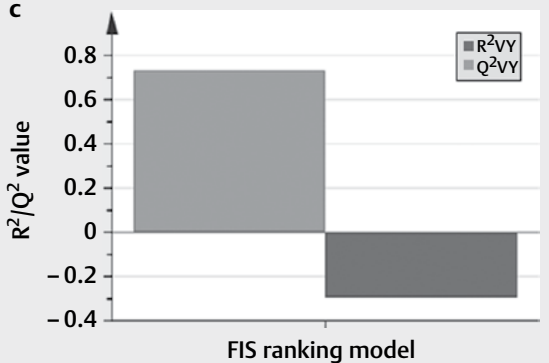

b

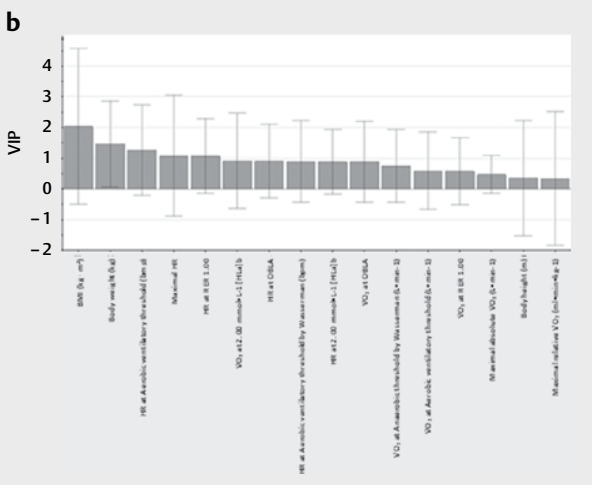

-Fig. 5 Predicted FIS slalom ranking for females age 16. a) Correlation between actual and predicted FIS ranking in April (1 $1^{\text {th }}$ list) based on preseason physical testing (model from $>$ Table 2). b) VIP summarizes the importance of the X-variables (physical tests), both for the $X$ - and $Y$-models $(X=16, Y=1 ; n=10)$. Tests with VIP $>1$ are the most relevant for explaining $Y$. The VIP values reflect the importance of terms in the model both with respect to $\mathrm{Y}$, i. e., its correlation to all the responses and with respect to $\mathrm{X}$ (the projection). The plot is displayed with $95 \%$ jackknife uncertainty bars. c) Overview plot shows the cumulated $\mathrm{R}^{2}$ and $\mathrm{Q}^{2}$ values for the model. Consensus: The observed correlation between actual and predicted FIS ranking (A) occurred by chance due to a large variation in the data (B) and low predictive power (C). 


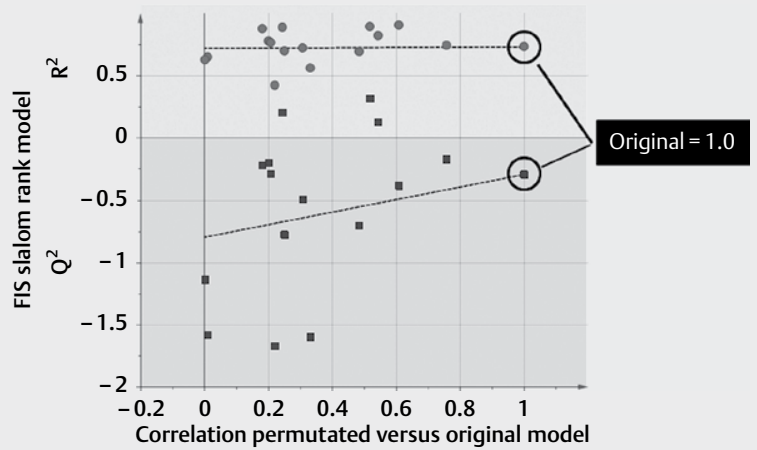

- Fig. 6 Validation of predicted FIS slalom ranking for females age 16. Female's slalom model shown as an example of cross-validation by 15 permutations (one less cycle than $\mathrm{X}$, the number of physical tests). The plot indicates the risk that the current OPLS model is spurious, i.e., the model just fits the training set well but does not predict $Y$ well for new observations. Goodness-of-fit $\left(R^{2}\right.$ and $\left.Q^{2}\right)$ of the original model is compared with the goodness-of-fit of 15 models based on data where the order of the $\mathrm{Y}$ observations has been randomly permuted, whereas the $\mathrm{X}$ matrix has been kept intact. For the selected $\mathrm{Y}$-variable (female slalom), on the vertical axis, the values of $\mathrm{R}^{2}$ and $\mathrm{Q}^{2}$ for the original model (far to the right) and of the $\mathrm{Y}$-permuted models further to the left. The horizontal axis shows the correlation between the permuted $\mathrm{Y}$-vectors and the original $\mathrm{Y}$ vector for the selected $Y$. The original $Y$ correlates 1.0 with itself, defining the high point on the horizontal axis. The plot above strongly indicates that the original model is NOT valid. The criteria for validity are: All blue $\mathrm{Q}^{2}$ values to the left are lower than the original points to the right, or the blue regression line of the $\mathrm{Q}^{2}$ points intersects the vertical axis (on the left) at or below zero.

Even though both the aerobic and anaerobic energy systems help to maintain energy levels during alpine skiing $[3,6,21,26,33,38]$, it has repeatedly been shown that maximal aerobic tests cannot adequately predict future competitive performance. A possible explanation is that improvements in $\dot{\mathrm{V}}_{2 \max }$, lactate threshold, and maximal anaerobic power, beyond a certain point, ultimately do not lead to a significant increase in race performance. Furthermore, in agreement with several previous findings [2, 21, 24, 30, 34], this study shows that the average alpine skier does not exhibit exceptionally high $\dot{\mathrm{V}}_{2 \text { peak }}$ values. An explanation for the inconsistencies between studies may stem from small sample sizes in noisy global data, resulting in a type I error [18]. Because there are fundamental differences in study designs and participants' characteristics, including $\dot{\mathrm{V}}_{2 \max } 2,21,24,26$, $30,34]$, standardized, common testing criteria are also difficult to propose. Cross-validation by permutation supports these suggestions ( $\vee$ Fig. 6), where the observed regression model is not confirmed, and the weak prediction power validated.

One limitation of this study is the use of BMI as an anthropometric predictor of performance, especially because BMI tends to overestimate adipose tissue in individuals with large muscle mass and a low body fat percentage (such as athletes) $[25,43]$. However, because no measurement of body composition other than body mass and stature were recorded, we chose to include calculated BMI in the statistical analysis, because somatotypes [8] and various anthropometric variables (including BMI) has previously been shown to affect the sport-specific performance in alpine skiing $[4,40]$. The focus of this study was aerobic variables as these are commonly used predictors of future athletic performance by alpine coaches and federations. Still, the lack of comprehensive anaerobic test results can be viewed as a limitation.

To be of real practical use, exercise testing must also be valid and reliable. Therefore, the presented workflow and analytical procedures, including multivariate statistical methods, can be used as a starting point for a global, more holistic view on performance evaluation [17]. Considering the time, effort and resources allocated to exercise testing of athletes around the world, validated procedures should be the minimum requirement of federations, coaches, and athletes. Well-executed meta-analyses for the selection of candidate tests, followed by larger-scale interventions, can find valid and reliable physiological tests for evaluation of current, and prediction of future, athletic performance.

In summary, none of the included variables predicted competitive alpine skiing performance. Cross-validation by permutation confirmed the lack of validity in observed multivariate statistical models. We suggest that the relevance of current modes of aerobic and anaerobic testing be re-considered. A valid and reliable test battery that can predict performance in alpine skiing seems to be lacking, both based on present and previously published data. Thus, future research directed towards screening for valid components of athletic performance is required. The results of this study should encourage future investigations to consider the predictive power of included test variables for the long-term, sport-specific performance in alpine skiing.

\section{Acknowledgements}

The authors wish to thank Daniel Lindberg, Sofie Henriksson, Malin Andersson, Sofia Pettersson and Catalina Fahlman for invaluable help with the data collection. No external funding sources were granted, there are no conflicts of interest, and the results of the present study do not constitute endorsement by ACSM.

\section{Conflict of Interest:}

The authors declare that they have no conflict of interest

\section{References}

[1] Alvarez-San Emeterio C, Antunano NP, Lopez-Sobaler AM, GonzalezBadillo JJ. Effect of strength training and the practice of Alpine skiing on bone mass density, growth, body composition, and the strength and power of the legs of adolescent skiers. J Strength Cond Res 2011; 25: 2879-2890

[2] Andersen RE, Montgomery DL. Physiology of Alpine skiing. Sports Med 1988; 6: 210-221

[3] Andersen RE, Montgomery DL, Turcotte RA. An on-site test battery to evaluate giant slalom skiing performance. J Sports Med Phys Fitness 1990; 30: 276-282

[4] Bandalo M, Lešnik B. The connection between selected anthropometric and motor variables and the competitive success of young competitors in alpine skiing. Kinesiologia Slovenica 2011; 17: 16-31 
[5] Boutin RD, Fritz RC. MRI of snow skiing and snowboarding injuries. Semin Musculoskelet Radiol 2005; 9: 360-378

[6] Brown SL, Wilkinson JG. Characteristics of national, divisional, and club male alpine ski racers. Med Sci Sports Exerc 1983; 15: 491-495

[7] Bylesjo M, Eriksson D, Sjodin A, Jansson S, Moritz T, Trygg J. Orthogonal projections to latent structures as a strategy for microarray data normalization. BMC Bioinformatics 2007; 8: 207

[8] Emeterio CA, Gonzalez-Badillo JJ. The physical and anthropometric profiles of adolescent alpine skiers and their relationship with sporting rank. J Strength Cond Res 2010; 24: 1007-1012

[9] Eriksson L, Byrne T, Johansson E, Trygg J, Vikström C. Multi- and Megavariate Data Analysis. Basic Principles and Applications. 3rd edMalmö: MKS Umetrics; 2013

[10] Ferguson RA. Limitations to performance during alpine skiing. Exp Physiol 2010; 95: 404-410

[11] Gross MA, Breil FA, Lehmann AD, Hoppeler H, Vogt M. Seasonal variation of VO 2 max and the VO2-work rate relationship in elite Alpine skiers. Med Sci Sports Exerc 2009; 41: 2084-2089

[12] Harriss DJ, Macsween A, Atkinson G. Standards for ethics in sport and exercise science research: 2018 update. Int J Sports Med 2017; 38: 1126-1131

[13] Haymes EM, Dickinson AL. Characteristics of elite male and female ski racers. Med Sci Sports Exerc 1980; 12: 153-158

[14] Högström GM, Pietilä T, Nordström P, Nordström A. Body composition and performance: influence of sport and gender among adolescents. J Strength Cond Res 2012; 26: 1799-1804

[15] Jolliffe IT. Principal Component Analysis. New York: Springer; 2010

[16] Kröll ], Birklbauer ], Stricker G, Müller E. Technique Training in Alpine Ski Racing: Forced Movement Changes by a Specific Device 2006;

[17] Lindberg AS, Oksa J, Antti H, Malm C. Multivariate statistical assessment of predictors of firefighters' muscular and aerobic work capacity. PLoS One 2015; 10: e0118945

[18] Loken E, Gelman A. Measurement error and the replication crisis. Science 2017; 355: 584-585

[19] Maffiuletti NA, Impellizzeri F, Rampinini E, Bizzini M, Mognoni P. Is aerobic power really critical for success in alpine skiing? Int J Sports Med 2006; 27: 166-167 author reply 168-169

[20] Muller E, Benko U, Raschner C, Schwameder H. Specific fitness training and testing in competitive sports. Med Sci Sports Exerc 2000; 32: 216-220

[21] Neumayr G, Hoertnagl H, Pfister R, Koller A, Eibl G, Raas E. Physical and physiological factors associated with success in professional alpine skiing. Int J Sports Med 2003; 24: 571-575

[22] Neumayr G, Hoertnagl H, Raas E. The Authors' Reply - Letter to the Editors.. Int J Sports Med 2006; 27: 168-169

[23] Plisk S. Physiological training for competitive alpine skiing. Natl Strength Cond Ass ] 1988; 10: 30-33

[24] Polat M. An examination of respiratory and metabolic demands of alpine skiing. J Exerc Sci Fit 2016; 14: 76-81

[25] Romero-Corral A, Somers VK, Sierra-Johnson J, Thomas RJ, CollazoClavell ML, Korinek J, Allison TG, Batsis JA, Sert-Kuniyoshi FH, Lopez-Jimenez F. Accuracy of body mass index in diagnosing obesity in the adult general population. Int J Obes (Lond) 2008; 32: 959-966

[26] Saibene F, Cortili G, Gavazzi P, Magistri P. Energy sources in alpine skiing (giant slalom). Eur J Appl Physiol Occup Physiol 1985; 53 : 312-316
[27] Seifert ], Kroll ], Muller E. The relationship of heart rate and lactate to cumulative muscle fatigue during recreational alpine skiing. J Strength Cond Res 2009; 23: 698-704

[28] Severini TA. Analytic Methods in Sports: Using Mathematics and Statistics to Understand Data From Baseball, Football, Basketball, and Other Sports. Boca Raton: CRC Press; 2015

[29] Spencer MR, Gastin PB. Energy system contribution during 200- to 1500-m running in highly trained athletes. Med Sci Sports Exerc 2001; 33: 157-162

[30] Spirk S, Steiner G, Tschakert G, Gröschl W, Schippinger G, Hofmann P. Oxygen uptake during race-like alpine giant slalom skiing in relation to variables of the human power spectrum. In: Müller $\mathrm{E}$, Lindinger $\mathrm{S}$, Stöggl T. eds. Science and Skiing V. Maidenhead: Meyer \& Meyer Sport (UK) Ltd; 2012: 418-425

[31] Steadman JR, Swanson KR, Atkins JW, Hagerman GR. Training for Alpine skiing. Clin Orthop Relat Res 1987; 34-38

[32] Szmedra L, Im J, Nioka S, Chance B, Rundell KW. Hemoglobin/ myoglobin oxygen desaturation during Alpine skiing. Med Sci Sports Exerc 2001; 33: 232-236

[33] Tesch P, Larsson L, Eriksson A, Karlsson J. Muscle glycogen depletion and lactate concentration during downhill skiing. Med Sci Sports 1978; 10: 85-90

[34] Tesch PA. Aspects on muscle properties and use in competitive Alpine skiing. Med Sci Sports Exerc 1995; 27: 310-314

[35] Triba MN, Le Moyec L, Amathieu R, Goossens C, Bouchemal N, Nahon P, Rutledge DN, Savarin P. PLS/OPLS models in metabolomics: The impact of permutation of dataset rows on the K-fold cross-validation quality parameters. Mol Biosyst 2015; 11: 13-19

[36] Trygg J, Holmes E, Lundstedt T. Chemometrics in metabonomics. J Proteome Res 2007; 6: 469-479

[37] Turnbull JR, Kilding AE, Keogh JW. Physiology of alpine skiing. Scand ] Med Sci Sports 2009; 19: 146-155

[38] Veicsteinas A, Ferretti G, Margonato V, Rosa G, Tagliabue D. Energy cost of and energy sources for alpine skiing in top athletes. J Appl Physiol Respir Environ Exerc Physiol 1984; 56: 1187-1190

[39] von Duvillard SP. Introduction: The interdisciplinary approach to the science of Alpine skiing. Med Sci Sports Exerc 1995; 27: 303-304

[40] White AT, Johnson SC. Physiological comparison of international, national and regional alpine skiers. Int J Sports Med 1991; 12: 374-378

[41] White AT, Johnson SC. Physiological aspects and injury in elite Alpine skiers. Sports Med 1993; 15: 170-178

[42] White GE, Wells GD. The effect of on-hill active recovery performed between runs on blood lactate concentration and fatigue in alpine ski racers. J Strength Cond Res 2015; 29: 800-806

[43] Whitlock EP, Williams SB, Gold R, Smith PR, Shipman SA. Screening and interventions for childhood overweight: a summary of evidence for the US Preventive Services Task Force. Pediatrics 2005; 116: e125 144

[44] Wold S. Cross-validatory estimation of the number of components in factor and principal components models. Technometrics 1978; 20 : 397-405

[45] Wold S, Sjöström M, Eriksson L. PLS-regression: a basic tool of chemometrics. Chemometr Intell Lab Syst 2001; 58: 109-130 